\title{
Sensitivity Analysis on the Impact of User Control on Daylight and Energy Simulations
}

\author{
Sahar Abdelwahab ${ }^{1}$, Peter Rutherford ${ }^{2}$, Mohammed Mayhoub ${ }^{1}$, Sergio Altomonte ${ }^{3}$ \\ ${ }^{1}$ Faculty of Engineering, Architecture Department, Al-Azhar University, Cairo, Egypt \\ ${ }^{2}$ Department of Architecture and Built Environment, University of Nottingham, Nottingham, UK \\ ${ }^{3}$ Architecture et Climat, Faculty of Architecture, Architectural Engineering and Urban Planning, \\ Université catholique de Louvain, Brussels, Belgium
}

\begin{abstract}
Whilst simulation techniques for predicting building performance are maturing, questions still arise as to how key input assumptions, such as user control, ultimately affect the resultant predictions. A sensitivity analysis was performed to identify the impact of blinds control on daylighting and energy simulations. The analysis was performed on a side-lit office with simple and complex façade systems. Daylighting simulations were conducted using RADIANCE, while energy analysis was run through EnergyPlus. The study found statistical evidence that blinds' control influenced the evaluation of building performance, particularly for facade designs with no external shading. The impact of user control was highly dependent on the facade system, orientation, and climate.
\end{abstract}

\section{Introduction}

Simulation tools are becoming available and accessible to non-expert users to evaluate building performance. However, most simulations have intrinsic uncertainties due to the unavoidable approximation of calculation engines (Tregenza, 2017) and the often unclear principles upon which model parameters (Ibarra and Reinhart, 2009) and simulation settings (Jones and Reinhart, 2017) are selected. For example, many core input parameters are often left to their default settings. Also, the assumptions defining input parameters, on which the calculations are based, can lead to unreliable simulation estimates if not precisely determined. To reduce the errors expected from simulations, there is a need to carefully define these assumptions and to trade-off the outcomes in order to improve simulation accuracy (Tregenza, 2017).

One of the further sources of uncertainty in simulations is represented by the behaviour of occupants and their interactions with environmental control systems. In fact, predicting building performance in isolation to human behaviour, using standardised fixed conditions as simulation input assumptions, may result in inaccurate evaluations that do not reflect actual performance in use (Tregenza and Mardaljevic, 2018; ASHRAE, 2007). For instance, building users frequently activate daylightcontrol systems, such as blinds and shades, to regulate interior lighting and thermal conditions when excessive sunlight is received in the space. Such behaviour will therefore affect indoor light levels and potentially impact on heating/cooling requirements (Reinhart, 2004; Van Den Wymelenberg, 2012; Nezamdoost and Van Den Wymelenberg, 2017; Bourgeois et al., 2006; Wienold et al., 2011). Therefore, if user control is not properly considered when evaluating building performance, this can result in substantial discrepancies between simulated and measured data (Roetzel et al., 2010; Gaetani et al., 2016). The high level of uncertainty from user operation can severly impact on design decisions if these are uniquely taken based on simulated data at the early design development stages (Van Den Wymelenberg, 2012).

Human actions to control environmental conditions inside buildings are not yet thoroughly handled within simulation tools. Despite the existence of some databased models that might support the prediction of human behaviour, their use by practitioners is still very limited (Gaetani et al., 2016), although the need for a more accurate evaluation of building performance is featured in some building standards and codes (ASHRAE, 2007; IESNAI, 2012; CIBSE, 2015). Nevertheless, the most commonly used methods for performance evaluation assume the typical standard settings with blinds remaining in a fixed position (da Silva et al., 2012). In recent years, this has attracted attention, triggering research on modelling human actions and their integration in building simulations for more realistic evaluations (Haldi and Robinson, 2010; Nezamdoost and Van Den Wymelenberg, 2017).

\section{Blinds Control}

\section{Triggers of Blinds Control}

At a fundamental level, blinds are mostly operated to control unwanted solar radiation and to protect against discomfort glare and excessive heat gains (Inoue et al., 1988; Reinhart, 2003; Van Den Wymelenberg, 2012). The operation rate is mainly dependent on climate conditions, latitude and orientation, sky conditions, time of day and year, etc. (Van Den Wymelenberg, 2012; Nezamdoost and Van Den Wymelenberg, 2017). Additionally, factors including quality of view, privacy, floor level, external obstructions, etc., may play a role in whether blinds are left open or closed (Nezamdoost and Van Den Wymelenberg, 2017). Some studies have investigated the impact of façade components on blinds operation. Research by Singh et al. (2016) showed that glazing with a high visible transmittance can result in higher glare, which may lead to closing the blinds more frequently. Other studies in the literature show that some façade parameters (e.g. shading devices, window size, etc.) have an impact on the received glare (Wienold et al., 2011; Brotas and Rusovan, 2013), although this might not be directly correlated to blinds operation. There is still a gap in the understanding of facade characteristics and 
their likely impact on blinds operation rate (Van Den Wymelenberg, 2012).

Blinds control has been associated with external stimuli that can result in occupant discomfort. Variables including illuminance, solar irradiance, and glare indices, with various thresholds, have been correlated to blinds operation in the literature. As such, illuminance data has been commonly used to simulate the triggering of blinds based on vertical (Reinhart, 2003, Nezamdoost and Van Den Wymelenberg, 2017) and horizontal light incidence (Tzempelikos and Shen, 2013; Katsifaraki et al., 2017; Konstantzos et al., 2015). In addition, solar radiation transmitted through the window can be a major factor influencing indoor visual and thermal comfort (Katsifaraki et al., 2017). Several quantities of horizontal solar irradiance at the work plane (Reinhart, 2004), vertical solar irradiance transmitted inside or incident outside the window (Lee and Selkowitz, 1995; Wienold et al., 2011; da Silva et al., 2012; Tzempelikos and Shen, 2013), and solar irradiance falling on the occupant (Newsham, 1994) have been correlated to blinds occlusions for different thresholds. Among several quantities, the threshold of $50 \mathrm{~W} / \mathrm{m}^{2}$ received on the work plane is mostly adopted as a trigger for blinds occlusion (Reinhart, 2004; Wienold, 2007; Bourgeois et al., 2006; da Silva et al., 2012) as it represents, according to field studies, the point where blinds are often closed (Reinhart, 2003; Inoue et al., 1988). Furthermore, blinds operation has been correlated to glare indices such as the Daylight Glare Index (DGI), specifically for values of DGI higher than 20 (da Silva et al., 2012). Additionally, the Daylight Glare Probability (DGP) has also been used to trigger the closing of blinds when its value exceeds 0.35 (perceptible glare) (Wienold, 2007; Wienold et al., 2011) or 0.40 (disturbing glare) (Jakubiec and Reinhart, 2012).

In addition to controlling glare occurrence, some studies have quantitatively correlated blinds operation to overheating using indoor temperature (Katsifaraki et al., 2017). Solar irradiation has also been used as an indicator for thermal discomfort. According to Newsham (1994) and Inoue et al. (1988), field studies have shown that solar irradiance greater than $233 \mathrm{~W} / \mathrm{m}^{2}$ received on the occupants represents the point at which the maximum rate of blinds operation occurs, as it results in a $20 \%$ probability of blinds control. This threshold echoes the $20 \%$ PPD thermal comfort criterion of ISO Standard 7730 (Newsham, 1994).

\section{Blinds Control and Building Simulation}

Based on the previously mentioned variables, several models/algorithms that predict blinds control have been developed and integrated within building simulations for more reliable evaluation. For example, Reinhart (2004) proposed the model 'Lightswitch 2002' to predict dynamic personal response and control of light and blinds. The algorithm assumes blinds to be fully lowered as soon as the incoming direct solar irradiance exceeds $50 \mathrm{~W} / \mathrm{m}^{2}$ at the workplace. Later, Bourgeois et al. (2006) integrated the Lightswitch algorithm within building simulation to evaluate the impact of blinds control on whole building energy performance. An expanded version of the original Lightswitch model was proposed to further distinguish between a user who closes the blinds to avoid direct light on the workspace, and a user who closes the blinds once the DGP becomes disturbing (DGP>0.40) (Jakubiec and Reinhart, 2012). An alternative model was proposed by the Illuminating Engineering Society (IES LM-83) suggesting blinds closure whenever more than $2 \%$ of the analysis points receive direct sunlight of 1000 lux or more, unless the blinds are not installed or the criteria of Annual Sunlight Exposure (ASE) are already met (IESNAI, 2012).

With respect to different algorithms that were built either on illuminance, DGP, solar irradiance data, etc., variations in performance outcomes of daylight and energy might often emerge when these models are applied (Bourgeois et al., 2006; Wienold et al., 2011; da Silva et al., 2012). Interestingly, the resultant differences may even lead to opposing shading positions (Wienold, 2007). Variations in simulation outputs may occur even when the outcomes from some of these algorithms are compared to each other (Nezamdoost et al., 2014). In fact, there is no consensus on which criteria best predicts user actions, although some studies have attempted to define the best performing criterion balancing energy demands with user comfort (da Silva et al., 2012). There is, however, agreement that user actions affect building performance, leading to variations in daylight and energy predictions.

The resultant variations in simulation outcomes are a source of uncertainty for designers who seek a certain level of accuracy at each design stage. This poses the question of how these variations change our interpretation of a model's performance. The literature has not examined in detail how different blinds control input parameters and operation criteria might influence final simulation outcomes. Moreover, no consideration has been given to the influence of façade configurations on blinds activation and their likely impact on performance evaluation. A review of the literature thus raises the two questions. (1) How do controlling decisions impact on daylight and energy predictions and influence performance evaluation, particularly at an early stage of design? (2) Is blinds control, and its likely impact on building performance, affected by façade configurations? In response, this study aims to examine the influence of blinds control on building simulations, using key performance indicators of daylight and energy as decision making criteria, for different facade configurations.

\section{Methodology}

Annual daylight and energy simulations were performed using a reference office (Reinhart, 2013) under the hot climate of Cairo, Egypt, and the temperate conditions of Nottingham, UK, with east, south, and west orientations. Simulations were carried out for normally-occupied office schedules using the $8 \mathrm{am}-6 \mathrm{pm}$ occupancy model, with consideration of daylight savings for Nottingham.

Grasshopper (V.0.9.0076) was used to conduct the simulations through interfacing with the lighting modelling engine RADIANCE via the DIVA V.4 tool. 
For energy modelling, the Archsim plugin for Grasshopper was used to interface with EnergyPlus (V.8.2.7) where all energy simulations were run.

\section{Model parameters}

A reference office, of size $3.6 \mathrm{~m}(\mathrm{~W}) \times 8.2 \mathrm{~m}(\mathrm{~L}) \times 2.8 \mathrm{~m}(\mathrm{H})$, was used for the model. Materials' optical and thermal properties are shown in Table 1. No external obstructions were considered. Two façade designs with varying levels of complexity were utilised to examine the likely impact of different configurations on blinds operation rate. The first was a simple design featuring a fully-glazed façade. The second was a complex façade with an egg-crate louver system (Figure 1). The enclosed space featured six workstations in two rows facing the internal walls.


Figure 1: Simple and complex façade configurations.

Table 1: Optical and thermal properties of the model.

\begin{tabular}{|l|l|}
\hline Component & Properties \\
\hline Glazing & $\begin{array}{l}\text { Glazing Double Pane Clear: } \mathrm{T}_{\text {vis }}=80 \% ; \\
\text { SHGC }=72 \% \text {; U-value }=2.71 \mathrm{~W} / \mathrm{m}^{2} \mathrm{~K} .\end{array}$ \\
\hline Interior walls & $\begin{array}{l}\text { Lambertian diffuser with a } 50 \% \text { reflectance } \\
0.15 \mathrm{~m} \text { brick }\left(\mathrm{Y}=5.38 \mathrm{~W} / \mathrm{m}^{2} \mathrm{~K}\right),(\text { Adiabatic) }\end{array}$ \\
\hline Exterior wall & $\begin{array}{l}35 \% \text { reflectance } 0.15 \mathrm{~m} \text { brick, U-value }= \\
2.33 \mathrm{~W} / \mathrm{m}^{2} \mathrm{~K} .\end{array}$ \\
\hline Ceiling & $\begin{array}{l}\text { Lambertian diffuser with } 80 \% \text { reflectance } \\
0.2 \mathrm{~m} \text { concrete }\left(\mathrm{Y}=6.00 \mathrm{~W} / \mathrm{m}^{2} \mathrm{~K}\right),(\text { Adiabatic) }\end{array}$ \\
\hline Floor & $\begin{array}{l}\text { Lambertian diffuser with } 20 \% \text { reflectance } \\
0.2 \mathrm{~m} \text { concrete }\left(\mathrm{Y}=6 \mathrm{~W} / \mathrm{m}^{2} \mathrm{~K}\right),(\text { Adiabatic) }\end{array}$ \\
\hline Furniture & Opaque material with $50 \%$ reflectance \\
\hline Computers & Self-luminance of screen $=250 \mathrm{cdm}{ }^{2}$ \\
\hline Blinds & Total transmission=0.04, reflection=0.41 \\
\hline $\begin{array}{l}\text { External } \\
\text { ground }\end{array}$ & Lambertian diffuser with $20 \%$ reflectance \\
\hline
\end{tabular}

The reference office was assumed to be heated and cooled by an HVAC system during the hours of occupation. Setpoint temperatures for the Nottingham climate were $21^{\circ} \mathrm{C}$ for heating and $25^{\circ} \mathrm{C}$ for cooling based on the CIBSE Guide A (CIBSE, 2015). In accordance with the literature for Cairo, the setpoints were $22^{\circ} \mathrm{C}$ for heating and $26^{\circ} \mathrm{C}$ for cooling (Sherif et al., 2014). Four out of the six workstations were assumed to be constantly occupied (Reinhart, 2013) (see Figure 2) resulting in a peak occupancy of 0.13 person $/ \mathrm{m}^{2}$. The total internal appliance load was set at $8 \mathrm{~W} / \mathrm{m}^{2}$ corresponding to one EnergyStarrated LCD monitor and laptop per occupant present. The installed peak lighting power density was set at 11.38 $\mathrm{W} / \mathrm{m}^{2}$. The reference office was modelled with a dimming light control installed. Three light sensors were set at each workstation row. When daylight levels fell below the target of 300 lux, artificial lighting was switched on.

\section{Blinds Characteristics and Controlling Scenarios}

A roller blind was used in this study to shade the window when conditions giving rise to visual/thermal discomfort were present. This type of shading device was specifically chosen over other types of internal blinds as the published studies for roller shades are generally scarce, although this system is commonly used in perimeter offices (Konstantzos et al., 2015). The blinds were installed $0.1 \mathrm{~m}$ from the window, and were assumed to totally shade the glazed area when a predefined discomfort threshold was reached based on the following scenarios:

- Scenario 1 (SC.1): Evaluation based on blinds always opened or no blinds installed (baseline case).

- Scenario 2 (SC.2): The blinds were assumed to be fully lowered as soon as disturbing glare (i.e., DGP>0.4) was received, based on (Jakubiec and Reinhart, 2012), otherwise the blinds were kept open. DGP was measured from the perspective of two seated subjects (view positions 1 and 2) shown in Figure 2, at a head height of $1.2 \mathrm{~m}$. The location of the two subjects was near the window at a distance of $1.2 \mathrm{~m}$ perpendicular to the window direction (facing computer screens), where the sun was more likely to be in the field of view, severe glare/overheating sensation was more likely to occur, and, more importantly, both subjects had direct access to the internal blinds control (manual).

- Scenario 3 (SC.3): The blinds were controlled based on the criteria proposed by the IES LM- 83 standard (IESNAI, 2012) whenever more than $2 \%$ of the analysis points received direct sunlight of 1000 lux or more. The area of each desktop was around $1.7 \mathrm{~m}^{2}$ (which exceeds the $2 \%$ specified in IES LM-83). For this, annual hourly data for average direct illuminance were generated on each desktop sensor.

- Scenario 4 (SC.4): The blinds were controlled in accordance with the direct solar irradiance received on the desktop, based on the Lightswitch model (Reinhart, 2004). The scenario assumed that blinds were fully lowered when incoming direct solar irradiance above $50 \mathrm{~W} / \mathrm{m}^{2}$ hit the horizontal workplace of user 1 and 2. Otherwise, the blinds were kept open.

- Scenario 5 (SC.5): The blinds were assumed to be lowered as soon as sunlight of solar intensity $>233$ $\mathrm{W} / \mathrm{m}^{2}$ was received on occupants (Newsham, 1994; Inoue et al., 1988). Sensors for solar irradiance were located at the head height $(1.2 \mathrm{~m})$ of a sitting person.

- Scenario 6 (SC.6): The blinds were always closed.

As seen above, the proposed scenarios aim to prevent visual discomfort at the eye and desktop levels (scenario 2, 3, and 4), and to avoid overheating (scenario 5). Conversely, scenarios 1 and 6 represent the extreme cases for comparison. The measurements of illuminance and solar irradiance for SC. 3 and 4 were taken, at a height of $0.8 \mathrm{~m}$, on the desktop of users 1 and 2 (see Figure 2) divided by a grid of $0.6 \times 0.6 \mathrm{~m}$ for the simple façade and $0.4 \times 0.4 \mathrm{~m}$ for the complex one, consistent with a previous study from the authors (Abdelwahab et al., 2017). 


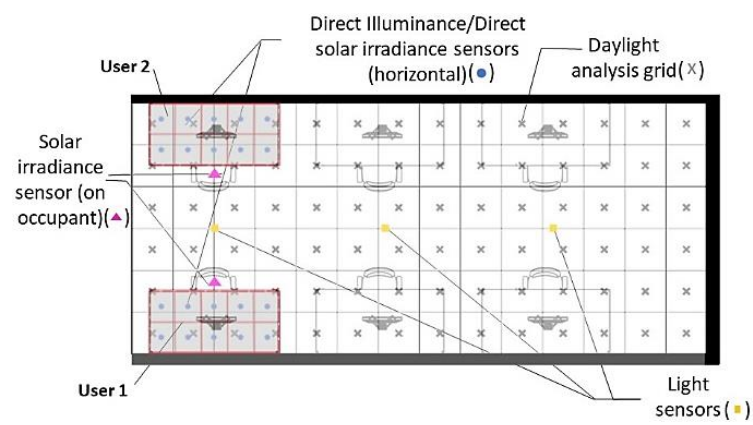

Figure 2: View positions (User1,2) and sensor positions. Shading Schedules

Different scenarios were integrated within daylight and energy simulation tools through the shading schedules that represent the data of blinds positioning for 8760 hours/year. The generation of the shading schedules was based on the pre-calculation of the different indicators of DGP, direct illuminance, and solar irradiance, for an hourly time step, received separately for a given façade configuration, orientation, and climate. For example, in order to calculate daylight and energy based on SC.2, hourly DGP values were pre-calculated from the perspective of subject 1 and 2 and converted into a separate schedule (shading schedule) where DGP values equal or higher than 0.4 were counted and replaced by 1 , which means blinds were closed, whereas DGP values less than 0.4 were replaced by 0 (blinds were open).

\section{Performance Indicators and Statistical analysis}

Daylight Autonomy (DA) was used to measure the percentage of the operation period that a daylight level was exceeded across the year. Conversely, spatial Daylight Autonomy (sDA) described the percentage of floor area receiving a target illumination for at least $50 \%$ of annual occupied hours (IESNAI, 2012). Energy use was calculated in terms of lighting, heating, and cooling loads, expressed in $\mathrm{kWh}$ per year per $\mathrm{m}^{2}$ of floor area.

The absolute Root-Mean-Square Error (RMSE) was used to examine the differences detected when comparing daylight estimates with and without blinds control. For energy loads, no reference suggests how high or low RMSEs should be for a simulation to be considered 'reliable'. Therefore, relative RMSE values were calculated to normalize the estimated errors from energy loads in relation to the predicted energy in the baseline case (with no blinds) to help interpret the results. The Cohen's d coefficient was used to estimate the effect size of the differences in daylight estimates simulated with and without blinds control. The interpretation of the effect size (d) was based on published benchmarks (Ferguson, 2009), where: $\mathrm{d}<0.41=$ negligible; $0.41 \leq \mathrm{d}<1.15=$ small; $1.15 \leq \mathrm{d}<2.70=$ moderate; $\mathrm{d} \geq 2.70=$ large.

\section{Results}

All cases with different controlling scenarios were analyzed for annual daylighting and energy simulation outcomes. The analysis was conducted separately for the simple and complex façade configurations. The results were statistically compared against the scenario with no blinds, which was used as a reference baseline case.

\section{Daylighting Simulation}

As expected, consideration of blinds control to prevent visual discomfort through a simple façade via scenarios 2 , 3 , or 4 , significantly reduced daylight estimates compared to the case that had a fixed condition with no blinds (SC.1). The analysis shown in Table 2 detected considerable errors under the Cairo climate, particularly for the south and west façades with RMSE varying between $20 \%$ and $39 \%$ for DA, this depending on the scenario applied. The estimated RMSEs were lower in the case of the east façade (RMSE 15\%-22\%). Among different controlling scenarios, SC.3 signalled the highest errors compared to the baseline case (SC.1), whereas the errors resulting from SC. 2 and SC. 4 were lower. When the differences were statistically measured, the effect size (Cohen's d) detected differences with small or moderate magnitude for DA under SC.2, 3 and 4, compared to SC.1. Interestingly, the errors in simulation outcomes were consistently lower under the Nottingham climate for the east and west facades (RMSE varied between 8\%-17\% DA). Only the errors for the south façade were more evident (RMSE varied between $22 \%-42 \%$ DA), with effect size estimates detecting differences of small to moderate magnitude. The example in Figure 3 illustrates the differences of DA, via a colour map, and the resultant sDA\% in accordance with the applied scenarios. As noted, ultimately daylight distribution across the floor area can vary considerably (14.3-100\%sDA) when considering blinds control, irrespective of the applied scenario. In essence, this shows how sensitive performance evaluation might be with respect to input parameters of user actions. This aspect can be critical when rating building performance, particularly considering that, for example, some certification systems such as LEED and WELL use sDA\% for accrediting indoor daylighting.



Figure 3: Simple façade configuration (Cairo): sDA\% for each controlling scenario in the south façade. 
In the case of the complex façade configuration, the analysis showed lower errors with RMSEs varying between $4.9 \%$ and $16 \%$ DA in Cairo and $3.3 \%$ and $13.4 \%$ DA in Nottingham, depending on the orientation. Both SC. 2 and 3 detected significant differences compared to SC.1, with small effect sizes for the south façade under both climates and for the west façade in Cairo. The differences were negligible for all other comparisons.

On the other hand, activating the blinds to control overheating via scenario SC.5 showed no or marginally low errors for both façade configurations under both climates compared to the baseline case (SC.1) (RMSEs $<2 \%$ DA) except for the case in the south façade under Cairo climate. In this particular case, the analysis showed errors with RMSE 6.6\% DA and differences characterised by small magnitude of effects. Otherwise, this scenario had no significant impact on any of the other cases.

Table 2: Comparisons between DA obtained with different controlling scenarios vs. SC.1.

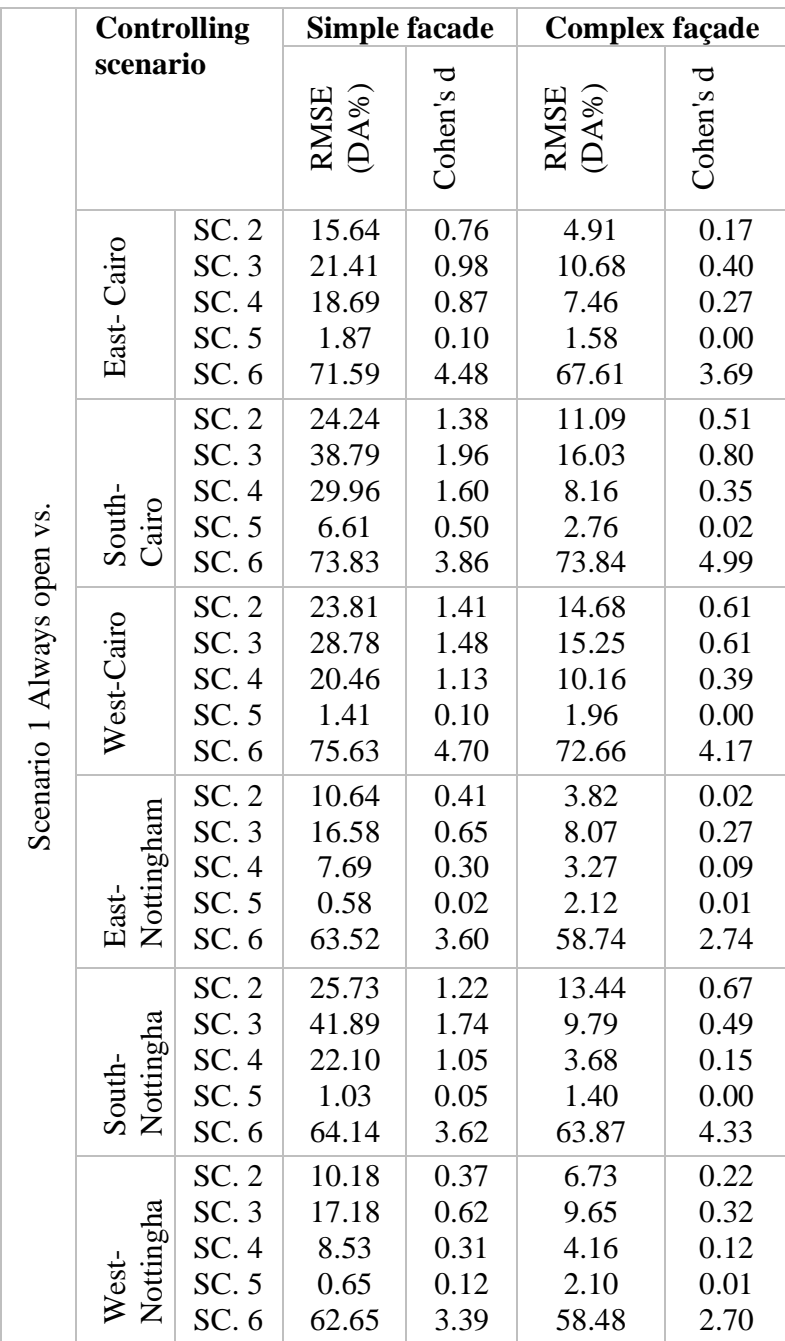

Lastly, the scenario with blinds always closed (SC.6) resulted in considerable differences compared to SC.1. The RMSE analysis detected errors higher than 58\% DA for both façade designs in all orientations under both climates. This led to significant differences in simulation outcomes with strong and moderate effects magnitude. This indicates that passive daylight control, represented in this extreme scenario, can cause major discrepancies between simulated and actual daylighting performance.

From the statistical analysis of the data, it can be inferred that user's actions to control blinds to avoid glare, via the specified scenarios based on DGP, direct illuminance, or direct solar irradiance, can significantly affect daylighting simulation outcomes compared to the case when blinds control is not considered, particularly for simple façade systems. The precision of daylighting simulation was less impacted in the case of complex façade designs, although substantive errors were detected in some cases based on the selected scenario.

\section{Energy Simulation}

During occupancy hours, no heating loads were detected for the specified set points under Cairo climate, complying with other studies in the literature conducted under the same climate with no or almost negligible heating requirements (Sherif et al., 2014). Conversely, for Nottingham, no cooling loads arose from the simulations for both façade designs in all tested orientations.

It should be noted that, irrespective of the scenario under examination, activating the blinds caused lighting loads to increase as a result of receiving lower levels of daylighting. Therefore, more lighting loads were used to maintain indoor lighting levels above the target illuminance (i.e., 300 lux). Cooling and heating loads were affected by blinds operation in different ways. Independently of lighting requirements and their thermal impact, activating the blinds can reduce solar heat transfer through the window, especially if shading devices are externally installed to prevent solar heat gains. The reduction in heat transfer from the window, however, is normally lower in the case of internal blinds because the heat has already been transferred into the space through the window (CIBSE, 2015). On the other hand, activating the blinds increases the use of artificial lighting that has constant heat radiation which, in turn, represents a source of heat that causes an increment in cooling or a decrement in heating loads (Bourgeois et al., 2006). In other words, blinds operation can either lower or raise heat input as it reduces heat transfer from the window, but at the same time, it increases heat gain from lighting luminaires that are switched on. The following sections show in detail the differences in energy loads deriving from blinds control compared to the baseline case with no blinds (SC. 1).

Lighting loads

For the case of the simple façade, the inferential data from Table 3 shows that activating the blinds to control visual discomfort via SC.2, SC.3, or SC.4 resulted in high RMSEs varying between $6.1-8.2 \mathrm{kWh} / \mathrm{m}^{2}$ (east), 9.7-16.3 $\mathrm{kWh} / \mathrm{m}^{2}$ (south), and 5.9-9.3 $\mathrm{kWh} / \mathrm{m}^{2}$ (west), depending on the scenario, compared to lighting loads obtained with no blinds (SC.1) under the Cairo climate. The estimated errors are equal or lower under the Nottingham climate. For the case of the complex facade, RMSEs varied between 3.9-6.9 $\mathrm{kWh} / \mathrm{m}^{2}$ (east), 3.9-7.8 $\mathrm{kWh} / \mathrm{m}^{2}$ (south) and 3.6-5.1 kWh/m² (west) in Cairo, while the impact was lower in Nottingham, with RMSEs ranging between 1.0$6.0 \mathrm{kWh} / \mathrm{m}^{2}$ for all orientations. For both façade 
configurations, the highest errors consistently occurred with SC.3 compared to SC1.

The statistical errors from SC.2, 3, 4, showed to be especially relevant for lighting energy modelling under the Cairo climate, particularly for the simple façade, relative to the lighting loads obtained without blinds (SC.1). This corresponded to an inflation in lighting loads by almost 1 to 5 times, depending on the scenario and the orientation. The impact was lower under the Nottingham climate with lighting loads errors of $35-81 \%$ (east), 90$179 \%$ (south), and 18-43\% (west), this again depending on the scenario under examination. The errors were lower for the case of the complex façade, likely due to the fact that the blinds have the least operation rate.

Activating the internal blinds to control overheating using SC.5 resulted in marginal errors in lighting energy loads with RMSEs $\leq 2.3 \mathrm{kWh} / \mathrm{m}^{2}$ compared to SC. 1 under all orientations. Considering the blinds always closed scenario (SC.6), this caused substantial differences to the case with the simple façade and no blinds (SC.1), with
RMSEs varying between 24.7-33.4 $\mathrm{kWh} / \mathrm{m}^{2}$ under the Cairo climate, this depending on orientation. The analysis in Nottingham led to errors of smaller scale. Lighting loads were lower by almost 5 to 10 times in Cairo, and by 2 to 3 times in Nottingham, in case of modelling lighting energy without considering blinds control (passive daylight use). The errors were generally of smaller magnitude for the complex façade, representing an increment by 3 to 7 times in Cairo and by almost 1 to 2 times in Nottingham, depending on the façade orientation.

These results suggest that integrating user actions to control visual discomfort is crucial for lighting energy modelling and, if not considered, it might mislead performance evaluation. However, consideration of all the metrics that are suggested in the literature as triggers to the activation of blinds control - i.e. DGP, direct illuminance, or direct solar irradiance - generally resulted in substantial errors in the simulated lighting energy loads under all the orientations tested compared to the case without blinds (or with blinds always open, SC.1).

Table 3: Comparisons between energy loads obtained with different controlling scenarios vs. SC.1.

\begin{tabular}{|c|c|c|c|c|c|c|c|c|c|c|c|c|c|c|c|}
\hline \multirow[b]{3}{*}{  } & \multirow[b]{3}{*}{ 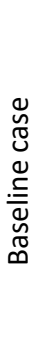 } & \multirow[b]{3}{*}{ 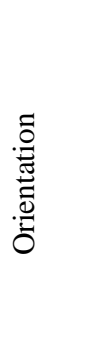 } & \multicolumn{7}{|c|}{ Simple façade } & \multicolumn{6}{|c|}{ Complex facade } \\
\hline & & & \multirow[b]{2}{*}{ 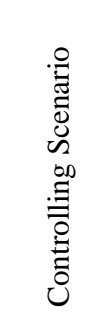 } & \multicolumn{2}{|c|}{$\begin{array}{l}\text { Lighting } \\
\text { Loads }\end{array}$} & \multicolumn{2}{|c|}{$\begin{array}{l}\text { Heating } \\
\text { loads }\end{array}$} & \multicolumn{2}{|c|}{$\begin{array}{c}\text { Cooling } \\
\text { loads }\end{array}$} & \multicolumn{2}{|c|}{$\begin{array}{l}\text { Lighting } \\
\text { loads }\end{array}$} & \multicolumn{2}{|c|}{$\begin{array}{l}\text { Heating } \\
\text { loads }\end{array}$} & \multicolumn{2}{|c|}{$\begin{array}{c}\text { Cooling } \\
\text { loads }\end{array}$} \\
\hline & & & & 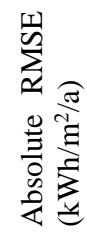 &  & 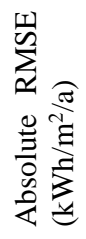 & 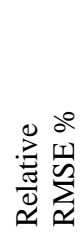 &  & 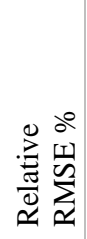 & 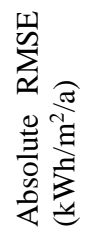 &  &  &  &  & 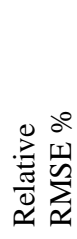 \\
\hline \multirow{3}{*}{ 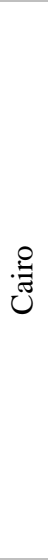 } & \multirow{3}{*}{ 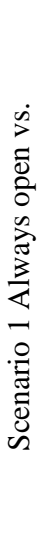 } & East & $\begin{array}{l}\text { SC. } 2 \\
\text { SC. } 3 \\
\text { SC. } 4 \\
\text { SC. } 5 \\
\text { SC. } 6\end{array}$ & $\begin{array}{r}6.09 \\
8.24 \\
6.14 \\
1.01 \\
24.65\end{array}$ & $\begin{array}{r}143 \% \\
194 \% \\
144 \% \\
24 \% \\
580 \%\end{array}$ & $\begin{array}{l}- \\
- \\
- \\
-\end{array}$ & $\begin{array}{l}- \\
- \\
- \\
- \\
-\end{array}$ & $\begin{array}{r}3.95 \\
5.73 \\
4.02 \\
0.68 \\
17.55\end{array}$ & $\begin{array}{r}7 \% \\
10 \% \\
7 \% \\
1 \% \\
30 \%\end{array}$ & $\begin{array}{r}3.93 \\
6.94 \\
5.21 \\
0.88 \\
27.89\end{array}$ & $\begin{array}{r}55 \% \\
97 \% \\
73 \% \\
12 \% \\
391 \%\end{array}$ & $\begin{array}{l}- \\
- \\
- \\
- \\
-\end{array}$ & $\begin{array}{l}- \\
- \\
- \\
- \\
-\end{array}$ & $\begin{array}{r}2.66 \\
4.47 \\
3.47 \\
0.76 \\
19.76\end{array}$ & $\begin{array}{r}5 \% \\
8 \% \\
6 \% \\
1 \% \\
36 \%\end{array}$ \\
\hline & & South & $\begin{array}{l}\text { SC. } 2 \\
\text { SC. } 3 \\
\text { SC. } 4 \\
\text { SC. } 5 \\
\text { SC. } 6\end{array}$ & $\begin{array}{r}9.70 \\
16.29 \\
12.39 \\
2.31 \\
31.02\end{array}$ & $\begin{array}{r}273 \% \\
458 \% \\
348 \% \\
65 \% \\
872 \%\end{array}$ & $\begin{array}{l}- \\
- \\
- \\
-\end{array}$ & $\begin{array}{l}- \\
- \\
- \\
- \\
-\end{array}$ & $\begin{array}{l}5.95 \\
5.06 \\
5.82 \\
3.65 \\
1.19\end{array}$ & $\begin{array}{l}3 \% \\
3 \% \\
3 \% \\
2 \% \\
1 \%\end{array}$ & $\begin{array}{r}5.49 \\
7.76 \\
3.88 \\
1.07 \\
34.54\end{array}$ & $\begin{array}{r}113 \% \\
160 \% \\
80 \% \\
22 \% \\
712 \%\end{array}$ & $\begin{array}{l}- \\
- \\
- \\
- \\
-\end{array}$ & $\begin{array}{l}- \\
- \\
- \\
- \\
-\end{array}$ & $\begin{array}{r}1.26 \\
2.30 \\
0.80 \\
0.43 \\
16.71\end{array}$ & $\begin{array}{r}1 \% \\
2 \% \\
1 \% \\
0 \% \\
14 \%\end{array}$ \\
\hline & & West & $\begin{array}{l}\text { SC. } 2 \\
\text { SC. } 3 \\
\text { SC. } 4 \\
\text { SC. } 5 \\
\text { SC. } 6\end{array}$ & $\begin{array}{r}7.04 \\
9.26 \\
5.90 \\
0.43 \\
33.35\end{array}$ & $\begin{array}{r}205 \% \\
270 \% \\
172 \% \\
12 \% \\
972 \%\end{array}$ & - & $\begin{array}{l}- \\
- \\
- \\
- \\
-\end{array}$ & $\begin{array}{l}5.56 \\
4.98 \\
4.98 \\
0.50 \\
4.60\end{array}$ & $\begin{array}{l}3 \% \\
3 \% \\
3 \% \\
0 \% \\
2 \%\end{array}$ & $\begin{array}{r}4.98 \\
5.12 \\
3.63 \\
0.83 \\
33.46\end{array}$ & $\begin{array}{r}87 \% \\
89 \% \\
63 \% \\
15 \% \\
583 \%\end{array}$ & $\begin{array}{l}- \\
- \\
- \\
- \\
-\end{array}$ & $\begin{array}{l}- \\
- \\
- \\
- \\
-\end{array}$ & $\begin{array}{r}0.00 \\
0.27 \\
0.06 \\
0.68 \\
14.29\end{array}$ & $\begin{array}{r}0 \% \\
0 \% \\
0 \% \\
1 \% \\
11 \%\end{array}$ \\
\hline \multirow{3}{*}{ 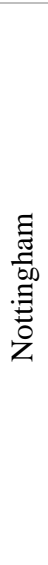 } & \multirow{3}{*}{  } & East & $\begin{array}{l}\text { SC. } 2 \\
\text { SC. } 3 \\
\text { SC. } 4 \\
\text { SC. } 5 \\
\text { SC. } 6\end{array}$ & $\begin{array}{r}5.82 \\
8.20 \\
3.53 \\
0.66 \\
25.94\end{array}$ & $\begin{array}{r}57 \% \\
81 \% \\
35 \% \\
7 \% \\
256 \%\end{array}$ & $\begin{array}{r}3.86 \\
5.61 \\
2.36 \\
0.44 \\
17.26\end{array}$ & $\begin{array}{r}4 \% \\
6 \% \\
2 \% \\
0 \% \\
18 \%\end{array}$ & $\begin{array}{l}- \\
- \\
- \\
- \\
-\end{array}$ & $\begin{array}{l}- \\
- \\
- \\
-\end{array}$ & $\begin{array}{r}4.88 \\
6.04 \\
1.8 \\
0.89 \\
24.48\end{array}$ & $\begin{array}{r}35 \% \\
43 \% \\
13 \% \\
6 \% \\
175 \%\end{array}$ & $\begin{array}{r}3.29 \\
4.07 \\
1.19 \\
0.59 \\
16.41\end{array}$ & $\begin{array}{r}3 \% \\
4 \% \\
1 \% \\
1 \% \\
17 \%\end{array}$ & $\begin{array}{l}- \\
- \\
- \\
- \\
-\end{array}$ & $\begin{array}{l}- \\
- \\
- \\
- \\
-\end{array}$ \\
\hline & & South & $\begin{array}{l}\text { SC. } 2 \\
\text { SC. } 3 \\
\text { SC. } 4 \\
\text { SC. } 5 \\
\text { SC. } 6\end{array}$ & $\begin{array}{r}9.88 \\
17.13 \\
8.61 \\
0.30 \\
28.1\end{array}$ & $\begin{array}{r}103 \% \\
179 \% \\
90 \% \\
3 \% \\
294 \%\end{array}$ & $\begin{array}{r}5.81 \\
6.38 \\
2.35 \\
0.07 \\
10.76\end{array}$ & $\begin{array}{r}13 \% \\
14 \% \\
5 \% \\
0 \% \\
24 \%\end{array}$ & $\begin{array}{l}- \\
- \\
- \\
- \\
-\end{array}$ & $\begin{array}{l}- \\
- \\
- \\
- \\
-\end{array}$ & $\begin{array}{r}5.87 \\
4.91 \\
2.09 \\
0.12 \\
27.97\end{array}$ & $\begin{array}{r}49 \% \\
41 \% \\
17 \% \\
1 \% \\
234 \%\end{array}$ & $\begin{array}{r}4.99 \\
3.52 \\
1.43 \\
0.01 \\
14.77\end{array}$ & $\begin{array}{r}8 \% \\
6 \% \\
2 \% \\
0 \% \\
23 \%\end{array}$ & $\begin{array}{l}- \\
- \\
- \\
- \\
-\end{array}$ & $\begin{array}{l}- \\
- \\
- \\
- \\
-\end{array}$ \\
\hline & & West & $\begin{array}{l}\text { SC. } 2 \\
\text { SC. } 3 \\
\text { SC. } 4 \\
\text { SC. } 5 \\
\text { SC. } 6\end{array}$ & $\begin{array}{r}2.54 \\
5.28 \\
2.22 \\
0.32 \\
26.92\end{array}$ & $\begin{array}{r}21 \% \\
43 \% \\
18 \% \\
3 \% \\
221 \%\end{array}$ & $\begin{array}{l}0.14 \\
1.36 \\
0.26 \\
0.26 \\
9.28\end{array}$ & $\begin{array}{r}0 \% \\
2 \% \\
0 \% \\
0 \% \\
16 \%\end{array}$ & $\begin{array}{l}- \\
- \\
- \\
- \\
-\end{array}$ & $\begin{array}{l}- \\
- \\
- \\
- \\
-\end{array}$ & $\begin{array}{r}1.83 \\
3.04 \\
0.96 \\
0.47 \\
24.05\end{array}$ & $\begin{array}{r}11 \% \\
19 \% \\
6 \% \\
3 \% \\
148 \%\end{array}$ & $\begin{array}{l}0.74 \\
1.29 \\
0.34 \\
0.29 \\
9.31\end{array}$ & $\begin{array}{r}1 \% \\
2 \% \\
0 \% \\
0 \% \\
13 \%\end{array}$ & $\begin{array}{l}- \\
- \\
- \\
- \\
-\end{array}$ & $\begin{array}{l}- \\
- \\
- \\
- \\
-\end{array}$ \\
\hline
\end{tabular}


The results also show the dependency of controlling decisions and their likely impact on lighting energy calculations based on different façade components. As such, the estimated errors were lower for the façade design with external shadings because these block the ingress of direct sunlight, reducing causes of discomfort that trigger blinds control. This outcome was consistent under both climates, although the results under the clearsky condition of Cairo were more clearly affected.

Heating and Cooling loads

The RMSE analysis illustrated in

Table 3 shows that using the blinds to prevent visual discomfort via SC.2, 3 or 4 in the case of the simple facade resulted in errors in heating loads between 2.4-5.6 $\mathrm{kWh} / \mathrm{m}^{2}$ in the east, $2.6-6.4 \mathrm{kWh} / \mathrm{m}^{2}$ in the south, and 0.1 $1.4 \mathrm{kWh} / \mathrm{m}^{2}$ in the west façade compared to the simulation results of SC.1. This represented 2-6\%, 5-14\%, and 0-2\% respectively of the heating loads obtained. In the case of the complex facade, the RMSE analysis produced errors lower than $5 \mathrm{kWh} / \mathrm{m}^{2}$ for all orientations, representing only $0-4 \%$ of the heating loads obtained under SC. 1 for the east and west facades, and 2-8\% for the south façade.

Using the same scenarios when modelling cooling energy use in Cairo, errors lower than $6 \mathrm{kWh} / \mathrm{m}^{2}$ for both façade designs, which represents less than $10 \%$ of the cooling loads obtained with no blinds were produced.

The SC.5 scenario produced almost no influence on the estimated heating and cooling loads. Closing the blinds during occupation time (SC.6) resulted in large differences in heating predictions compared to SC.1 with RMSEs ranging between $9.3-17.3 \mathrm{kWh} / \mathrm{m}^{2}$ in all orientations, corresponding to $16-24 \%$ of heating loads. The analysis of the complex façade led to similar results. In case of cooling loads, SC.6 caused more evident differences, with RMSE of $17.0 \mathrm{kWh} / \mathrm{m}^{2}$ in the east façade compared to SC.1. The impact was much lower for the south and west orientations $\left(<5 \mathrm{kWh} / \mathrm{m}^{2}\right)$. When testing the complex facade, RMSEs were between 14.3 and $19.8 \mathrm{kWh} / \mathrm{m}^{2}$ in all orientations, representing almost $11 \%-36 \%$ of the cooling energy obtained with SC. 1 .

These results indicate that modelling heating and cooling requirements in isolation of user actions, based on the scenarios explored in this study, has a relatively lower impact than lighting loads on simulation outcomes, except for the case with passive daylight users who always draw the blinds during the occupation time.

\section{Discussion and Conclusion}

Using sensitivity analysis techniques, the impact of blinds control on daylight and energy simulations was statistically measured. The main findings from this study suggest that individual controlling decisions to prevent causes of visual discomfort from the window, based on the scenarios tested, are crucial in building simulations that drive decision making. A significant discrepancy was statistically detected between the simulated data with and without the integration of user control, leading to sizeable discrepancies of indoor daylighting levels and estimation of lighting energy requirements.
Controlling the blinds to limit heat transfer from the window was found to have a marginal or no effect on simulation outcomes for all orientations and façade types. Generalisation of these inferences should, however, be treated with caution as they largely vary depending on the climatic conditions. As such, the errors in daylighting levels (DA) and lighting energy were more evident under the hot climate condition of Cairo and reduced dramatically under the temperate climatic condition of Nottingham, irrespective of the scenario applied. This suggests that the impact of blinds control on the reliability of light and energy simulations can be more significant under clear skies. In terms of façade components, simulation outcomes were significantly impacted by blinds control for simple façades exposed directly to the sun. The impact was lower, yet still significant, in the case of external shading (complex façade) because this configuration limits the ingress of excessive sunlight.

From the wide range of statistical differences in daylighting and energy outcomes detected in this study, it can be concluded that building performance evaluation is always likely to be subject to uncertainty from user control. In response, some approaches suggest defining this range in simulations as the worst/best case scenario of occupant behaviours since the real behaviour will lie somewhere between those boundaries (Roetzel et al., 2010). However, it should be noted that, in reality, the impact of manipulating shading systems on building performance can be much higher especially if blinds are manually controlled. In this case blinds controlled manually might often be kept down until the end of the day, even after discomfort issues from daylight have been resolved (Reinhart, 2003). This was examined in this study using the scenario with a passive daylight user, who leaves the blinds closed (SC.6). This scenario ultimately led to relevant differences in daylighting levels and lighting energy loads. Although this represents an extreme case, it showed how the use of blinds can substantially impact on building performance. Moreover, people are less likely to interrupt their work in order to manually operate the blinds, especially if the controlling point is not easily accessible or the mechanism is not easy to manoeuvre (Bordass et al., 1994). This suggests that the influence of activating blinds may inflate as a result of keeping the blinds down for longer occupational times. With respect to the variations in simulation outputs resulted from each scenario separately, further field studies are needed to identify the scenario (e.g. DGP, etc.) that best predicts user action, so the gap between predicted and measured building performance can be reconciled.

\section{References}

Abdelwahab, S., Kent, M. G. and Altomonte, S. (2017). Sensitivity Analysis for the Daylight Simulation of Complex Façades. Advanced Building Skins. Bern.

Ashrae (2007). Addendum $r$ to ANSI/ASHRAE/IESNA Standard 90. 1-2007 EnergyStandard for Buildings Except Low-Rise Residential Buildings

Bourgeois, D., Reinhart, C. and Macdonald, I. (2006). Adding advanced behavioural models in whole 
building energy simulation: A study on the total energy impact of manual and automated lighting control. Energy and buildings, 38, 8.

Brotas, L. and Rusovan, D. Parametric daylight envelope. PLEA, 2013.

Cibse (2015). Environmental design: CIBSE Guide A. London: The Chartered Institution of Building Services Engineers.

Da Silva, P. C., Leal, V. and Andersen, M. (2012). Influence of shading control patterns on the energy assessment of office spaces. Energy and Buildings, 50.

Ferguson, C. J. (2009). An effect size primer: A guide for clinicians and researchers. Professional Psychology: Research and Practice, 40(5), 532.

Gaetani, I., and Hensen, L. (2016). Occupant behavior in building energy simulation:towards a fit-for-purpose modeling strategy. Energy and Buildings, 121.

Haldi, F. and Robinson, D. (2010) On the unification of thermal perception and adaptive actions. Building and Environment, 45(11), 2440-2457

Ibarra, D. and Reinhart, C. F. (2009). Daylight factor simulations-how close do simulation beginners 'really'get? Building Simulation, Vol. 196, p. 203.

Iesnai (2012). IES Spatial Daylight Autonomy (sDA) and Annual Sunlight Exposure (ASE). New York, NY, USA: IESNA Lighting Measurement.

Inoue, T., Kawase, T., Ibamoto, T., Takakusa, S. and Matsuo, Y. (1988). The development of an optimal control system for window shading devices based on investigations in office buildings. ASHRAE transactions, 94, 1034-1049.

Jakubiec, J. A. and Reinhart, C. F. (2012). The 'adaptive zone'-A concept for assessing discomfort glare throughout daylit spaces. Lighting Research and Technology, 44(2), 149-170.

Jones, N. L. and Reinhart, C. F. (2017). Experimental validation of ray tracing as a means of image-based visual discomfort prediction. Building and Environment, 113.

Katsifaraki, A., Bueno, B. and Kuhn, T. E. (2017). A daylight optimized simulation-based shading controller for venetian blinds. Building and Environment, 126, 207-220.

Konstantzos, I., Tzempelikos, A. and Chan, Y.-C. (2015). Experimental and simulation analysis of daylight glare probability in offices with dynamic window shades. Building and Environment, 87, 244-254.

Lee, E. S. and Selkowitz, S. E. (1995). The design and evaluation of integrated envelope and lighting control strategies for commercial buildings ASHRAE Transactions, IL 101 (1), 326-342.

Newsham, G. R. (1994). Manual control of window blinds and electric lighting: implications for comfort and energy consumption. Indoor Environment, 3(3).
Nezamdoost, A., Mahic, A. and Van Den Wymelenberg, K. Annual energy and daylight impacts of three manual blind control algorithms. 2014 IES Annual Conference Proceedings. Pittsburg, PA, 2014.

Nezamdoost, A. and Van Den Wymelenberg, K. (2017). Blindswitch 2017: Proposing A New Manual Blind Control Algorithm for Daylight and Energy Simulation.

Reinhart, C. F. (2004). Lightswitch-2002: a model for manual and automated control of electric lighting and blinds. Solar energy, 77(1), 15-28.

Reinhart, C. F., \& Voss, K. (2003). Monitoring manual control of electric lighting and blinds. Lighting research \& technology, 35(3), 243-258.

Reinhart, C. F., Jakubiec, J. A., \& Ibarra, D. Definition of a reference office for standardized evaluations of dynamic façade and lighting technologies. In Proceedings of BS2013: 13th Conference of International Building Performance Simulation Association, 2013 France.

Roetzel, A., Tsangrassoulis, A., Dietrich, U. and Busching, S. (2010). A review of occupant control on natural ventilation. Renewable and Sustainable Energy Reviews, 14, 1001-1013.

Sherif, A., Sabry, H., Arafa, R. and Wagdy, A. Energy efficient hospital patient room design: effect of room shape on window-to-wall ratio in a desert climate. 30th International PLEA Conference: Sustainable Habitat for Developing Socities-Choosing The Way Forward. India, 2014.

Singh, R., Lazarus, I. and Kishore, V. (2016). Uncertainty and sensitivity analyses of energy and visual performances of office building with external venetian blind shading in hot-dry climate. Applied Energy, 184.

Tregenza, P. (2017). Uncertainty in daylight calculations. Lighting Research \& Technology, 49, 829-844.

Tregenza, P. and Mardaljevic, J. (2018). Daylighting buildings: Standards and the needs of the designer. Lighting Research \& Technology, 50, 63-79.

Tzempelikos, A. and Shen, H. (2013). Comparative control strategies for roller shades with respect to daylighting and energy performance. Building and Environment, 67.

Van Den Wymelenberg, K. (2012). Patterns of occupant interaction with window blinds: A literature review. Energy and Buildings, 51, 165-176.

Wienold, J. Dynamic simulation of blind control strategies for visual comfort and energy balance analysis. Building Simulation, 2007.

Wienold, J., Frontini, F., Herkel, S. and Mende, S. (2011). Climate based simulation of different shading device systems for comfort and energy demand. 12th Conference of International Building Performance Simulation Association. 